\title{
Reconhecimento e ato infracional na adolescência: reflexões iniciais
}

\author{
ALYSSON ASSUNÇÃO ANDRADE ${ }^{I}$ \\ e JACQUELINE DE OLIVEIRA MOREIRA ${ }^{I I}$
}

\section{Introdução}

A QUESTÃO do adolescente identificado com a criminalidade tem sido um tema de estudo de diferentes áreas no cenário brasileiro. Segundo o mapa da violência, o homicídio é a principal causa de mortes não naturais e violentas entre os jovens brasileiros. A cada 100 mil jovens, 53,4 foram assassinados em 2011. Os crimes foram praticados contra pessoas entre 14 e 25 anos. Segundo o mapa, o aumento da violência entre pessoas dessa faixa etária demonstra a omissão da sociedade e do poder público em relação aos jovens. De acordo com o estudo, a partir do esquecimento e da omissão passa-se, de forma fácil, à condenação o que representa só um pequeno passo para a repressão e punição.

Além disso, não é difícil verificarmos que as atuais discussões que envolvem a criminalidade na adolescência adquirem, por vezes, contornos valorativos recheados de preconceitos, intolerância e disseminação do ódio aos diferentes modos de ser da juventude; e isso principalmente nos países ditos periféricos, que trazem em sua história uma longa tradição de segregação, de desigualdade social, de precária oferta de escolarização ou de melhores condições de vida para as classes pobres.

Com isso, surge a necessidade de se pensar e intervir junto aos adolescentes que cumprem medidas socioeducativas, com vistas a auxiliar o adolescente a construir outras saídas para sua vida. Vale dizer, as medidas socioeducativas representam a ação legal do Estado brasileiro para trabalhar junto ao adolescente que comete um ato infracional (ação análoga ao crime) sua responsabilização jurídica e subjetiva pelo ato transgressor. E, como tais, essas medidas são preconizadas pelo Estatuto da Criança e do Adolescente (ECA), promulgado em 1990, legislação brasileira de vanguarda que responde às diretrizes estabelecidas pela Organização das Nações Unidas (ONU) para o cuidado de crianças e adolescentes. O estatuto considera crianças e adolescentes como sujeitos em desenvolvimento sendo urgente e necessário garantir seus direitos e apresentar seus deveres. 
Entretanto, como nos orientam inúmeros teóricos e pensadores da contemporaneidade, pode-se dizer que vivemos, de maneira geral, em uma sociedade que se mostra marcada por um crescente esvaziamento do sentido das ações humanas nos espaços públicos. Nessa direção, Dejours (1999) nos diz que a atualidade traz, em seu bojo, a existência de um "sofrimento ético" que corresponde à traição de ideais e valores apreendidos com nobres (aprovadores e perpetuados pela tradição); valores esses que atravessam os indivíduos em todos os âmbitos de sua vida. Bauman (2008), por sua vez, relata que uma imediata fluidez, fragilidade e transitoriedade em construção marcam todas as espécies de vínculos sociais que, uma década atrás, se combinaram para construir um arcabouço duradouro e fidedigno dentro do qual se podia tecer uma rede de interações humanas.

Como consequência dessa fragilização dos laços sociais, o que encontramos agora, segundo Bauman (2009), é um tipo de sociedade em que as diferentes formas de manifestação de violência, de criminalidade, de insegurança, de medo, de discriminação e de injusta social tornam-se cada vez mais permanentes.

Sendo assim, em razão dos incontáveis e imensos desafios que a temática da violência coloca para os grandes centros urbanos contemporâneos, diferentes pesquisadores de variadas correntes e áreas das ciências humanas têm se debruçado sobre esse tema a fim de descortinar e melhor compreender a imbricada articulação que se opera entre juventude e criminalidade. Nessa direção, os trabalhos Francischini e Campos (2005); Segalin e Trzcinski (2006), Evangelista (2008); Moreira, Rosário e Costa (2008); Branco e Wagner (2009), Guerra et al. (2010); Esmeraldo (2011); Monte et al. (2011); Minahim e Spostato (2011); Vaz e Moreira (2015); Reis e Melo (2017), confirmam a importância do tema para a comunidade científica brasileira.

Referendados nesses estudos e em outros que contemplam essa temática, e tendo como aporte teórico fundamental a psicanálise freudiana, bem como os profícuos trabalhos de Charles Taylor e Axel Honneth no que se refere à problemática do reconhecimento, vislumbrada aqui enquanto uma categoria fundamental da modernidade no que se refere à produção de subjetividade, procuraremos traçar, mesmo que em linhas gerais, algumas chaves teórico-compreensivas na tentativa de elucidar a questão do ato infracional na juventude pela via interdisciplinar do conhecimento, dada a complexidade e as múltiplas determinações psicossociais que acabam por compor esse fenômeno.

Destacamos, entretanto, que estamos cientes das profundas diferenças que há entre os campos teóricos. Todavia, optamos por manter no foco o tema proposto, a saber, a possível articulação entre busca de reconhecimento e ato infracional juvenil e manejar as teorias como ferramentas que nos auxiliem na construção do nosso edifício especulativo. Assim, iniciamos o nosso trabalho com uma breve exposição da teoria do reconhecimento na perspectiva de Hegel, Taylor e Honneth, reconhecendo, todavia, os limites da apresentação panorâmi- 
ca que não faz justiça à complexidade do pensamento de cada autor. Em seguida, traçamos algumas considerações sobre o tema a partir da teoria psicanalítica, e isso sob a óptica de Freud e Winnicott. Por fim, procuramos demonstrar como a construção de um diálogo entre esses diferentes campos do saber pode ser mostrar frutífero para se pensar o fenômeno do ato infracional na juventude, para além de uma abordagem circunstancial e reducionista.

\section{Hegel e a origem do reconhecimento}

A emergência da teoria de reconhecimento, enquanto uma elaboração filosófica e ético-política, se consolidou, pela primeira vez na história do pensamento moderno, a partir do século XIX, com a filosofia de G. W. F. Hegel, marcadamente em sua obra Fenomenologia do espirito (publicada em 1807), onde a "Dialética do senhor e do escravo" - capítulo IV dessa mesma obra - mostra-se como o paradigma fundamental da nova forma de se conceber a constituição do sujeito (e de suas inter-relações) na sociedade.

Nessa sua grande obra, Hegel irá descrever, de uma forma muito precisa e esclarecedora, a dialética que se opera no processo do reconhecimento. Por vezes, essa dialética se opera mediante uma luta de vida ou de morte. Quer dizer, segundo o filósofo de Stuttgart,

[...] enquanto agir do Outro, cada um tende, pois, à morte do Outro. Mas aí está também presente o segundo agir, o agir por meio de si mesmo, pois aquele agir do Outro inclui arriscar a própria vida. Portanto, a relação das duas consciências-de-si é determinada de tal modo que elas se provam a si mesmas e uma a outra através de uma luta de vida ou morte. (Hegel, 2003, p.128, $\$ 187)$

Seguindo Ribeiro (2012), podemos dizer que, no jogo intersubjetivo que se opera na Dialética do Senhor e do Escravo, o Senhor se constitui como tal ao se defrontar, enquanto consciência-de-si, com outra consciência-de-si que não ele mesmo, com outro $\mathrm{Eu}$. Vale dizer,

[...] outro $e$ u que, não sendo coisa, se interpõe a seu desejo e assim o ameaça. Surge, então, a exigência de um luta de vida e morte. Essa luta é assumida de maneira diferente por cada um. Aquele que será o senhor a aceita como necessária e a leva até o fim, indiferente à sua própria vida. O que será o escravo teme a possibilidade de morte. Antes da luta pelo reconhecimento não existe nem senhor e nem escravo. Mas um dos lutadores torna-se escravo reconhecendo o senhorio do outro. Na verdade, quem mantém a indiferença, a coragem e a vontade de lutar mesmo com o risco da morte e até o fim é o vencedor, o senhor. Quem é derrotado e prefere se submeter ao outro a morrer é o escravo. (Ribeiro, 2012, p.162 e 163)

Compreendido dessa maneira, o relacionamento entre Senhor e Escravo não é, para Hegel, a proposta, a completa assimilação e vivência concreta da intersubjetividade. Na verdade, como bem destaca Ribeiro (2012), a lição hegeliana é a de que na violência e na dominação não é possível a plena realização do reconhecimento. É a comunidade ética o lugar do pleno reconhecimento, ou 
melhor, do reconhecimento recíproco. Isto é, a comunidade é o lugar onde os sujeitos se reconhecem reciprocamente. Essa, por sua feita, é uma comunidade de sujeitos, "é o lugar onde os indivíduos, consciência-de-si, partilham convicções, costumes, tradições, instituições" (Ribeiro, 2012, p.165).

Para Vaz (1981), a dialética do Senhor e do Escravo, tal como forjada por Hegel, assinala a emergência, na textura de um discurso, por assim dizer, de extrema tecnicidade, de um desses veios profundos da filosofia não escrita que correm ao longo da cultura ocidental. Como tais, esses veios assinalam a continuidade de certas experiências fundadoras que sustentam e orientam o relevo de determinado solo cultural. Nesse sentido, aponta o autor,

A dialética do Senhor e do Escravo aflora na superfície do texto de Hegel a partir desse veio muito profundo ou dessa experiência fundadora que configura as sociedades ocidentais desde a sua aurora grega como sociedades politicas, ou seja, sociedades constituídas em torno da luta pelo reconhecimento, oscilando entre os polos da physis que impele a particularidade do interesse e do desejo, e do nomos que rege a universalidade do consenso em torno do bem reconhecido e aceito. (Vaz, 1981, p.7-8)

A partir dessa formulação filosófica paradigmática do mundo ocidental, lançada primordialmente por Hegel, é que Charles Taylor e Axel Honneth, principalmente na década de 1990, reacendem a discussão sobre a Teoria do Reconhecimento a fim de torná-la uma chave compreensiva fundamental para se compreender e interpretar os conflitos e embates sociais vivenciados pelos mais variados agrupamentos humanos que habitam o globo terrestre com suas formas de ser culturalmente múltiplas e absolutamente singulares. Vejamos, então, como cada autor se apropria do fecundo pensamento de Hegel.

\section{Charles Taylor: reconhecimento e constituição das identidades}

Descrito como um dos maiores protagonistas do debate político-filosófico da contemporaneidade, o filósofo e historiador canadense Charles Taylor destaca-se como um intelectual que se propõe a pensar as dificuldades e os desafios que atravessam o atual cenário mundial globalizado. Nesse sentido, ao colocar-se enquanto um pensador continuamente disposto a estabelecer um diálogo multicultural, social e político, Taylor busca conceber uma ética que prima pelo reconhecimento das diferenças culturais, morais e comportamentais existentes entre os diferentes povos e nações.

Como um pensador de herança hegeliana, Taylor realiza um profundo estudo historiográfico da modernidade visando desvelar quais os fatores tornaram-na possível. Nesse empreendimento intelectual e filosófico, a política de reconhecimento emerge como uma das mais importantes contribuições desse filósofo canadense às demandas das políticas democráticas atuais.

Segundo Taylor (1998), a exigência do reconhecimento na atualidade adquire certa premência devido à suposta relação entre reconhecimento e identidade, significando esse último termo qualquer coisa como a maneira como uma 
pessoa se define, como é que as suas características fundamentais fazem dela um ser humano. Nesse contexto, os indivíduos e grupos não lutam apenas para obterem o reconhecimento de suas diferenças. As lutas por reconhecimento se entrelaçam também com lutas pela distribuição tanto do poder político, quanto do bem-estar econômico.

A grande problemática em relação ao reconhecimento, ou da falta dele, e sua relação com a construção da identidade dos indivíduos é expressa por Taylor quando ele nos diz que a nossa identidade é formada, em parte, pela existência ou inexistência de reconhecimento e, muitas vezes, pelo reconhecimento incorreto dos outros, "podendo uma pessoa ou grupo de pessoas serem realmente prejudicadas, serem alvo de uma verdadeira distorção, se aqueles que os rodeiam reflectirem uma imagem limitada, de inferioridade ou de desprezo por eles mesmos" (Taylor, 1998, p.45). Por isso o pensador canadense argumenta que o não reconhecimento ou o reconhecimento incorreto pode afetar negativamente o indivíduo, bem como ser uma forma de agressão, ao reduzir a pessoa a uma maneira de ser que é falsa, distorcida, e que restringe a sua real potencialidade.

Dessa forma, Taylor demonstra que a centralidade da questão do reconhecimento, assim como a necessidade de sua emergência nos diferentes espaços públicos da vida cotidiana dos agentes sociais, é de crucial importância para as ações políticas concretas dos municípios, estados, nações e agências internacionais, visto que os danos causados pelo não reconhecimento podem ser catastróficos para inúmeras pessoas, grupos e civilizações. Vale dizer, o reconhecimento incorreto não implica só uma falta do respeito devido. Ele pode também marcar as suas vítimas de maneira absolutamente cruel, "subjugando-as através de um sentimento incapacitante de ódio contra elas mesmas. Por isso, o respeito devido não é um acto de gentileza para com os outros. É uma necessidade humana vital" (Taylor, 1998, p.46).

Em Taylor (1998), a noção do reconhecimento traz um precioso enfoque na intersubjetividade, destacando o caráter relacional e agonístico da construção da sociedade, pois esse atento teórico canadense está preocupado com os processos de construção do self ao defender que os indivíduos dependem do reconhecimento intersubjetivo para se autorrealizarem, e isso tanto em âmbito pessoal quanto em âmbito social-coletivo.

A política de reconhecimento, tal como proposta por Taylor (1998), apresenta-se como um misto das políticas da dignidade universal e das políticas da diferença. Ora, as primeiras estão relacionadas, segundo o próprio Taylor (1998), com a substituição do valor da honra (até então ligada a uma sociedade que atrelava a identidade à posição social) pela noção de dignidade, que passa a ter um caráter universal e igualitário no qual todos possam compartilhar. Já as segundas relacionam-se com a mudança que possibilitou o reconhecimento de uma nova interpretação do conceito de dignidade, a partir da noção da auten- 
ticidade, que estabeleceu a ideia de identidade individualizada que, de acordo com o filósofo canadense, é aquela que o sujeito reconhece como particularmente sua, que ele descobre em si mesmo, caracterizando-se como uma nova forma de subjetividade, na qual o interior possui respostas para os questionamentos do indivíduo. Dessa maneira, o discurso sobre o reconhecimento chega até nós, indivíduos contemporâneos, caracterizado em dois níveis: "primeiro, na esfera íntima, onde a formação da identidade e do ser é entendida como fazendo parte de um diálogo e lutas permanentes como os outros-importantes; e, depois, na esfera pública, onde a política do reconhecimento igualitário passou a desempenhar um papel cada vez maior" (Taylor, 1998, p.57).

Tal como veremos em seguida em Honneth (2003), a teoria do reconhecimento emerge em Taylor (1998) sempre como uma contínua luta intersubjetiva. Isso significa que o reconhecimento não pode ser plenamente alcançado, cedido ou doado, pois ele não está restrito a fins específicos, nem é limitado a conquistas na esfera de direitos garantidos pelo Estado. Ele não é um prêmio final que liberta os indivíduos. A luta por reconhecimento pode ter muitas manifestações diferentes, na medida em que ela não é senão um processo permanente em que a sociedade reflexivamente se transforma e altera padrões de relação social. Por isso, admitir que se trata de uma luta intersubjetiva é assumir que ela se constrói na relação com o outro. É perceber que os objetivos, as estratégias e as próprias identidades não estão postos de antemão, mas se constroem na ação conjunta.

Assim, a construção da identidade, na perspectiva concebida por Taylor (1998), passa, necessariamente, pelo contínuo processo dialético do reconhecimento que, enquanto tal, possui a capacidade de moldar, quando o reconhecimento é legítimo e verdadeiro, ou deformar os sujeitos, caso seja um reconhecimento distorcido e errôneo, ou simplesmente inexistente. Por isso a dinâmica do reconhecimento é vista por Taylor como uma necessidade humana vital, já que as formações das identidades individuais e grupais estão diretamente ligadas a ele.

\section{Axel Honneth e a luta por reconhecimento}

O filósofo e sociólogo frankfurtiano Axel Honneth (2003), ao escrever, em 1992, a sua obra de maior renome no cenário internacional, Luta por reconhecimento: a gramática moral dos conflitos sociais, inspira-se no conceito de reconhecimento do jovem Hegel e com ele busca fundamentar a sua própria versão da teoria crítica contemporânea no que diz respeito aos impasses vivenciados cotidianamente pelos indivíduos na sociedade. Com esse escrito, Honneth pretende explicar as mudanças sociais por meio da luta por reconhecimento e propõe uma concepção normativa de eticidade a partir de diferentes dimensões de reconhecimento (Salvadori; Honneth, 2001). Vale dizer, os indivíduos e os grupos sociais somente poderão formar a sua própria identidade quando forem, dialeticamente falando, reconhecidos intersubjetivamente. 
Para Honneth (2003), existem três formas, ou dimensões de reconhecimento, que se localizam em diferentes esferas e apresentam uma relação de codependência, a saber: a esfera emotiva, a esfera jurídica-moral e a esfera da estima social ou da solidariedade.

Desenvolvendo de maneira mais acurada cada uma dessas esferas que compõem o processo dialético de reconhecimento, Honneth (2003) nos diz que, em relação à primeira esfera, o que está em questão são as emoções primárias, como o amor e a amizade. Para melhor desenvolver o seu pensamento, o autor volta-se para os trabalhos do psicanalista inglês Donald Winnicott, que realizou uma profícua investigação no campo da psicologia infantil. Nessa direção, Salvadori e Honneth (2011, p.190) nos esclarecem que, para Honneth:

O ponto de partida dessa primeira forma é uma fase de simbiose, chamada por Winnicott "dependência absoluta". A mãe e o filho estão em um estado de indiferenciação. As reações do filho são percebidas pela mão como um único ciclo de ação. Winnicott chama isso "intersubjetividade primária", em que há uma unidade de comportamento. Porém, para ampliar o seu campo social de atenção, a mãe começa a romper a sua identificação com o bebê. Com isso, o bebê aprende que a mãe é algo do mundo e que não está à sua inteira disposição.

Após esse momento, surge a segunda fase, chamada por Winnicott de "dependência relativa". É nesse período, como pontuam Salvadori e Honneth (2011, p.190), que a criança desenvolve a sua capacidade para uma ligação afetiva. Vale dizer:

A criança reconhece o outro como alguém com direitos próprios, independente. Para Winnicott, a fim de alcançar essa independência do outro, a criança tem que desenvolver dois mecanismos psíquicos: destruição e os fenômenos e objetos transicionais. A destruição (mordidas no corpo da mãe) consiste em atos que a criança pratica quando descobre a independência da mãe. Eles se tornam positivos quando o bebê reconhece a independência da mãe, amando-a sem as fantasias de onipotência. Os fenômenos e objetos transicionais (travesseiro, brinquedo, dedo polegar) são elos de mediação entre a fase da fusão e a da separação.

De acordo com o psicanalista inglês, a criança somente alcança a criatividade quando fica sozinha com os objetos transicionais. E isso é possível devido à dedicação emotiva da mãe, mesmo estando distante da criança. Quer dizer, "essa confiança na dedicação materna faz com que a criança desenvolva a autoconfiança” (ibidem).

Inspirando-se na análise de Winnicott, Honneth (2003) acaba por concluir que o amor, tal como vivenciado na experiência infantil da criança, é uma forma de reconhecimento. Será por meio desse afeto, inclusive, que o indivíduo desenvolverá uma confiança em si mesmo, indispensável para seus projetos de autorrealização pessoal. E como elucidam Salvadori e Honneth (2011), para Honneth o amor somente surge quando a criança reconhece o "outro como 
uma pessoa independente, ou seja, quando não está mais num estado simbiótico com a mãe. O amor é o fundamento da autoconfiança, pois permite aos indivíduos conservarem a identidade e desenvolverem uma autoconfiança, indispensável para a sua autorrealização. O amor é a forma mais elementar de reconhecimento" (Salvadori; Honneth, 2011, p.190).

Na segunda etapa do processo dialético, quer dizer, na fase do direito, o reconhecimento ocorre porque há respeito. Contudo, tanto na esfera emotiva quanto na jurídico-moral, "somente há autonomia quando há o reconhecimento da autonomia do outro" (ibidem, p.191). Para Honneth (2003), nessa segunda esfera, a pessoa passa a ser reconhecida como autônoma e moralmente imputável, visto que desenvolveu os sentimentos de autorrespeito.

Já na esfera da estima social, terceira e última esfera do reconhecimento, encontramos aquilo que Honneth (2003) caracteriza como a fase da aceitação recíproca das qualidades individuais, julgadas a partir dos valores existentes na comunidade. Na perspectiva de Salvadori e Honneth (2011, p.191), o filósofo frankfurtiano estabelece que por meio dessa esfera "gera-se a autoestima, ou seja, uma confiança nas realizações pessoais e na posse de capacidades reconhecidas pelos membros da comunidade".

No entender de Honneth (2003), a luta pelo reconhecimento sempre se inicia, então, quando surge a experiência do desrespeito em uma dessas esferas, tendo em vista que a autorrealização dos indivíduos somente poderá ser alcançada quando há, na esfera do amor, a possibilidade de autoconfiança; na esfera jurídico-moral, o autorrespeito; e na esfera da solidariedade, a autoestima.

Entretanto, de acordo com Nobre (2003), somente nas duas últimas esferas do processo dialético de reconhecimento é que há a possibilidade da luta ganhar contornos de um conflito social, isso porque, na primeira esfera, teríamos o estabelecimento das "primeiras relações sociais como um processo de afastamento dos sujeitos das determinações naturais" (Nobre, 2003, p.49). Quer dizer, para esse autor, o pensamento hegeliano vê a relação de "pais e filhos" como uma “ação recíproca universal e de formação dos homens" (ibidem), onde o sujeito, ao receber a acolhida do outro, se percebe como um ser de carências.

Consequentemente, pode-se dizer que o reconhecimento, no âmbito jurídico-moral, que constitui a segunda esfera, está intimamente relacionado à esfera emotiva, representante da primeira forma de socialização do sujeito e localizada no interior da família, visto que é através do amor e da percepção de sua carência como estrutural pelos seres mais próximos que os sujeitos estarão aptos a expandir essas relações para a sociedade. Segundo Honneth (2003, p.50), verificamos que "o caminho que conduz à nova relação social é descrito como um processo de universalização jurídica: as relações práticas que os sujeitos já mantinham com o mundo na $1^{a}$ etapa são arrancadas de suas condições de validade meramente particulares e transformadas em pretensões de direito universais, contratualmente garantidas”. 
Assim compreendidos, os movimentos de socialização do reconhecimento, segundo a perspectiva de Honneth (2003), realizam uma operação dialética em relação ao reconhecimento particular que se encontra no seio da família. Nessa direção, alguns elementos são preservados e outros ultrapassados. Mas, devido ao excesso de particularidade do reconhecimento familiar, o autor considera, inspirado em Hegel, que o crime, no sentido estrito, só pode "ser pensando como uma ação que visa desconsiderar a $2^{\text {a }}$ etapa de reconhecimento" (Honneth, 2003, p.53).

Vale dizer, para Hegel, a origem do crime se encontra no fato de o processo dialético de reconhecimento ter sido incompleto. Nesse sentido, Honneth (2003) assevera que para o filósofo de Stuttgart a ação agressiva com que o sujeito excluído responde não tenta lesar a propriedade alheia por satisfação de suas necessidades sensíveis. A reação destrutiva daquele que não foi reconhecido visa, contudo, um dar-se a conhecer novamente ao outro. Ou seja, um ato cujo verdadeiro objetivo é recuperar a atenção do outro. Nas palavras de Honneth, recuperando Hegel, "o excluído lesa a posse do outro; ele coloca seu ser-para-si excluído nisso, seu meu (SeinMein). Ele destrói algo nisso, [um] aniquilar como o do desejo, para dar-lhe seu sentimento de si, mas não seu sentimento de si vazio, senão que pondo seu si em um outro si, no saber de um outro" (Hegel, 2003 apud Honneth, 2003, p.88).

Honneth (2003), então, vê no crime um representante do ato, consequência de uma lesão no "ser reconhecido-universal". Para o autor, se efetuaria no crime (numa etapa avançada do direito), o mesmo que na luta de vida e de morte. Isto é, sob as condições do processo de formação individual, "um sujeito procura, mediante uma ação provocadora, levar o outro indivíduo ou os muitos associados a respeitar o que não foi ainda reconhecido nas próprias expectativas pelas formas de relacionamento social" (Honneth, 2003, p.101).

Ao comentar a formulação desse proeminente pensador de Frankfurt, Salvadori e Honneth $(2011$, p.191) nos dizem que, em Honneth, para cada esfera de reconhecimento (amor, jurídico-moral e estima social) há, via de regra,

[...] uma autorrelação prática do sujeito (autoconfiança nas relações amorosas e de amizade, autorrespeito nas relações jurídicas e autoestima na comunidade social de valores). A ruptura dessas autorrelações pelo desrespeito gera as lutas sociais. Portanto, quando não há um reconhecimento ou quando esse é falso, ocorre uma luta em que os indivíduos não reconhecidos almejam as relações intersubjetivas do reconhecimento. Toda luta por reconhecimento inicia por meio da experiência de desrespeito. $\mathrm{O}$ desrespeito ao amor são os maus-tratos e a violação, que ameaçam a integridade física e psíquica; o desrespeito ao direito são a privação de direitos e a exclusão, pois isso atinge a integridade social do indivíduo como membro de uma comunidade político-jurídica; o desrespeito à solidariedade são as degradações e as ofensas, que afetam os sentimentos de honra e dignidade do indivíduo como membro de uma comunidade cultural de valores. 
Portanto, ao seguir as ideias de Hegel, Honneth (2003) afirma que a eticidade é o conjunto de condições intersubjetivas, que funcionam como condições normativas necessárias à autodeterminação e a autorrealização. Nesse sentido, os conflitos sociais surgem quando há o desrespeito a qualquer uma das formas de reconhecimento, ou seja, de experiências morais decorrentes da violação de expectativas normativas, tendo em vista que a identidade moral dos indivíduos e, por conseguinte, das comunidades, é formada por essas expectativas. Assim, por meio da vida boa, então, chegamos a uma conciliação entre liberdade pessoal e valores comunitários.

\section{Reconhecimento, ato infracional e psicanálise}

Diante do exposto até aqui, levantamos a hipótese de que os atos infracionais dos adolescentes podem estar vinculados às diferentes etapas de reconhecimento e revelam a face mortífera da segregação social, incluindo em seu interior um campo de indeterminação não capturável. Entretanto, apesar de considerar tal hipótese, não deixamos de apostar numa abordagem e compreensão desse fenômeno, presente no mundo juvenil contemporâneo, que prime pela análise interdisciplinar do ato infracional nessa fase do desenvolvimento psicossexual humano que é atravessada por grandes transformações tanto de ordem física quanto de ordem social e subjetiva na vida dos sujeitos.

Dessa forma, ao partirmos do fenômeno da violência e articulando-o ao tema da segregação, julgamos ser de grande relevância utilizarmos, como operador conceitual, a teoria do reconhecimento, tal como proposta por Hegel (2003) e perpetrada por Taylor (1998) e Honneth (2003). Tal arcabouço teórico, a nosso ver, mostra-se muito bem contemplado, por exemplo, na frase de Célio Garcia, citada por Vorcaro, Mazzinni e Monteiro (2008), onde ele nos diz que "a vida do crime [...] é severa, violenta e insegura; no entanto, oferece um sossego temporário e instável a todo aquele que desejar ser reconhecido" (Garcia, 2000 apud Vorcaro; Mazzinni; Monteiro, 2008).

Bem, como de conhecimento público, a teoria psicanalítica, desde sua inauguração com Freud, discorre sobre a singularidade de cada caso. Por meio dela, sabe-se que as influências de determinado evento dependerão da forma como o sujeito, a partir de sua história, se apropriará dele. Por sua vez, a compreensão do sintoma dos adolescentes em situação de vulnerabilidade como um ato a ser escutado e reconhecido, merece, entretanto, possuir um tratamento conceitual ampliado. Vale dizer, além da história singular do sujeito, uma análise interdisciplinar do ato infracional na juventude faz-se necessária, tendo em vista que uma única perspectiva teórica jamais se mostra capaz de desvelar um determinado fenômeno em si mesmo. Sustentar tal postura epistemológica significa, pois, reiterar que não acreditamos em uma linearidade causal unívoca para o fenômeno do crime, cuja complexidade aproxima-se mais de uma soma de vetores que se cruzam na composição relacional de seu resultado social. 
Realizada essa ressalva, e articulando o ato infracional como uma tentativa do sujeito de afirmar-se perante o outro, visto que se encontra em situação de vulnerabilidade tanto social quanto subjetiva, tal como pleiteia a teoria do reconhecimento, não podemos desconsiderar, contudo, que tal ato criminoso possa surgir como sintoma que necessita ser escutado, desde que isso seja realizado de uma maneira acurada pelo psicanalista cidadão, para utilizarmos uma expressão cunhada por Laurent (2010).

Isso posto, ao balizarmos a teoria psicanalítica com a dialética processual da teoria do reconhecimento, podemos dizer, juntamente com Hegel, Taylor e Honneth, que o Homem é, dada sua condição simbólico-cultural, um ser necessariamente reconhecido e necessariamente reconhecente; quer dizer, ele se constitui como um reconhecedor, uma vez que "o desenvolvimento da autoconsciência dependente da existência de um segundo sujeito: sem a experiência de um parceiro de interação que lhe reagisse, um indivíduo não estaria em condições de influir sobre si mesmo com base em manifestações autoperceptíveis" (Hegel, apud Honneth, 2003, p.131 grifo nosso).

O destaque concedido à palavra reagir não é aleatório, pois aqui entendemos a reação como um movimento que implica, necessariamente, a presença do outro de modo particularmente ativo. É nesse viés que Honneth insere a abordagem winnicottiana da psicanálise, para pensar as lutas por reconhecimento, enfatizando as relações de objeto presentes na construção teórica do psicanalista inglês.

Winnicott descreve o desenvolvimento psíquico do bebê a partir de estágios sucessivos que se estabelecem de maneira gradual, partindo de uma dependência absoluta em relação à mãe ou seu substituto, até a separação. A falta, portanto, é constituída no decorrer do desenvolvimento do bebê, "permitindo que a criança suporte a desilusão e perceba a incompletude do Outro" (Costa, 2007 , p.55). Será a continuidade dos cuidados que, para Winnicott, dará a sustentação psíquica da criança.

Com base nos estudos realizados por Winnicott, Honneth (2003) esboçará os princípios fundamentais do primeiro nível de reconhecimento, o amor. Nessa direção, Honneth (2003) nos lembra que Hegel supõe no amor o cerne estrutural de toda eticidade. Segundo o filósofo de Frankfurt, "só aquela ligação simbioticamente alimentada, que surge da delimitação reciprocamente querida, cria a medida de autoconfiança individual, que é a base indispensável para a participação autônoma na vida pública" (Honneth, 2003, p.178).

Nessa direção, Dias (2000) esclarece que uma das raízes da agressividade se encontra na constante falha do ambiente que deveria oferecer para o bebê uma saudável possibilidade de amadurecimento. E faz parte da tarefa da mãe suficientemente boa permanecer na relação suportando a agressividade e acolhendo a reparação oferecida pelo bebê. Essa sequencia machucar-e-curar repete-se inúmeras vezes e, gradualmente, o bebê passa a acreditar no esforço construtivo, 
a suportar a culpa e, assim, a tornar-se livre para o amor instintivo. Com isso, o movimento de se responsabilizar por seus instintos agressivos depende da capacidade do ambiente suportar as oscilações entre o machucar-e-curar.

Assim, a primeira forma de reconhecimento recíproco está alicerçada na segurança emocional viabilizada pela experiência intersubjetiva do amor, que "constitui o pressuposto psíquico do desenvolvimento de todas as outras atitudes de autorrespeito" (Honneth, 2003, p.177). Vale dizer,

[...] a forma do reconhecimento do amor que Hegel descreve como um 'ser-si-mesmo em um outro', designa um arco de tensões comunicativas que medeiam continuamente a experiência do poder-estar-só com a do estar-fundido. A referencialidade do eu e a simbiose representam os contrapesos exigidos que, tomados em conjunto possibilitam um recíproco estar-consigo-mesmo no outro. (Honneth, 2003, p.175)

Podemos pensar como seria a ausência de tal reconhecimento no plano primário, familiar, onde algo da transmissão do amor e da eticidade ficou incompleto. Nesse sentido, Lacan dá um novo passo. Para ele, trata-se por estrutura de falta de objeto, e não de relação de objeto. Se retornamos a Freud, a ideia de relação de objeto já é, em si mesma, um paradoxo. Freud isola o momento da perda do objeto do momento de seu reencontro. Com isso, demarca não apenas o caráter mítico dessa perda, como também a impossibilidade do reencontro com o objeto perdido. Em sua obra Três ensaios sobre a teoria da sexualidade (1905), Freud (1976b) se refere às transformações da puberdade e considera a memória latente nesse período sobre uma primeira experiência alucinatória de satisfação. Freud coloca que a relação modelar com o objeto primevo (a mãe) e sua rememoração são irreversíveis, no sentido de que o objeto será sempre um objeto reencontrado, marcado pelo estilo desse primeiro objeto. Daí o hiato insuperável entre o que se busca e o que se encontra. Daí a relação estrutural ser com a falta do objeto, e não com o objeto.

Em vista disso, a falta de objeto como causa se torna operatória no plano ético, na medida em que o desejo se articula a partir da Lei que o regula. Nesse plano, a função da família é a da transmissão da cultura, ou seja, de uma forma de contenção do gozo, cuja barreira é o desejo. Assim, é ela, a família, o primeiro vetor de transmissão da eticidade.

Nesse sentido, retomamos a importância desse primeiro nível de reconhecimento descrito por Honneth radicado na possibilidade da inscrição de uma referência no sujeito que balizará suas ações ao longo da vida. Tal referência garantirá a possibilidade de um encontro alteritário que implicaria, necessariamente, uma relação de reconhecimento recíproco. É necessário, porém, incluir aí a dimensão alteritária do sujeito com seu Outro, estabelecida a partir da relação com a falta de objeto, não prevista por Honneth. Dividido por seu desejo (Freud, 1976f), buscando a satisfação na recuperação pelo objeto perdido das primeiras satisfações libidinais, mas jamais reencontrado, uma parte do eu é des- 
conhecida pelo próprio sujeito, havendo, entre as instâncias de seu psiquismo, alternâncias, discordâncias, conflitos e tensões. Da tentativa de dar conta dessa realidade, a partir da nomeação do que se perde no encontro entre corpo e linguagem, o sujeito torna-se um estranho para si mesmo: duplo que lhe confere uma unidade irrecuperável, campo de indeterminação que agencia sua relação com o outro (Freud, 1976c).

Assim, o ato de separação comporta certa cota de agressividade destrutiva para que o sujeito se destaque do olhar do outro, constituindo o próprio corpo, duplicado dessa imagem original - apoiado nela, mas não todo correspondente a ela. Nesse hiato, sem sutura, entre o eu e a imagem do eu, radica a dimensão pulsional que resiste à significação e à determinação significante.

É importante salientar que localizamos aí o problema do ato infrator nos adolescentes, pois entendemos que a adolescência é um momento vulnerável da vida do sujeito, uma vez que solicita uma nova organização pulsional. O sujeito atravessa um momento conflitivo iniciado pela substituição gradual do corpo infantil, com o qual era identificado, para um corpo sexuado, o aumento da libido concorrendo com o afastamento dos objetos edípicos e a escolha de um novo objeto sexual não incestuoso, culminando na entrada efetiva na dialética social (Freud, 1976b). Dessa maneira, o ato infracional pode se abrir como uma possibilidade concreta de reconhecimento social, uma vez que a falta de reciprocidade estrutural no ato originário de reconhecimento é interpretada como recusa do outro, gerando sofrimento.

\section{Conclusão}

Excluídos dos espaços ofertados por uma sociedade capitalista, inúmeros jovens se encontram à margem do mercado de trabalho, mas também não têm acesso à educação, saúde, cultura e, por vezes, vivem em lares violentos. Não é incomum que esses jovens só têm acesso aos direitos previstos nos acordos mundiais de proteção à infância e adolescência, como acesso a educação, saúde, esporte, lazer, convivência familiar, no momento em que responde juridicamente por um ato infracional.

Enquanto um ideal colocado pela modernidade, pleiteia-se que os sujeitos, na condição de cidadãos dotados de uma dignidade iluminista inviolável, não sejam privados do reconhecimento, e isso tanto no nível individual quanto no nível coletivo. Essa concepção formal de eticidade, colocada desde Hegel, cuja pretensão de alcance seja universal, não desconsidera, entretanto, que os limites dados de antemão, pelas situações históricas concretas de cada sociedade, possam inviabilizar a completude do processo dialético de reconhecimento.

Assim, diante daquilo que procuramos expor ao longo do texto acima e considerando o atual e trágico cenário do crescimento da letalidade violenta entre os jovens no Brasil, parece-nos urgente intervir. É preciso, pois, pensar em estratégias que viabilizem um pacto contra a violência e a diminuição das mortes brutais e precoces de nossa juventude, sobretudo, negra e pobre. 
Referências

BANDEIRA, M. A. S. Atos infracionais e medidas socioeducativas: uma leitura dogmática, crítica e constitucional. Ilhéus: Editus, 2006.

BAUMAN, Z. Globalização: as consequências humanas. Rio de Janeiro: Jorge Zahar, 1999.

. Medo líquido. Rio de Janeiro: Jorge Zahar, 2008.

. Confiança e medo na cidade. Rio de Janeiro: Jorge Zahar, 2009.

BRANCO, B. M.; WAGNER, A. Os adolescentes infratores e o empobrecimento da rede social quando do retorno à comunidade. Ciência e Saúde Coletiva, Rio de Janeiro, v.14, n.2, p.557-66, 2009.

BROID, J. Adolescência e violência: a criação de dispositivos clínicos no território conflagrado das periferias. In: GURSKI, R.; ROSA, M. D.; POLI, M. C. (Org.) Debates sobre a adolescência contemporânea e o laço social. Curitiba: Juruá, 2012. p.123-36.

CALDEIRA, T. Cidade de muros: crime, segregação e cidadania em São Paulo. São Paulo: 34; Edusp, 2000.

COSTA, T. Psicanálise com crianças. Rio de Janeiro: Jorge Zahar, 2007.

DIAS, E. O. Winnicott: agressividade e teoria do amadurecimento. Revista Natureza Humana, São Paulo, v 2, n.1, p.9-48, 2000.

DEJOURS, C. A banalização da injustiça social. 2.ed. Rio de Janeiro: Editora da FGV, 1999.

ENGEL, N. A. Prática de ato infracional e as medidas socioeducativas: uma leitura a partir do estatuto da criança e do adolescente e dos princípios constitucionais. Itajaí, 2006. Dissertação (Mestrado) - Programa de Pós-Graduação em Ciências Jurídicas. Universidade do Vale do Itajaí. Itajaí, 2006.

ESMERALDO, M. B. S. Adolescência e ato infracional: a família em conflito. Natal, Dissertação (Mestrado) - Programa de Pós-Graduação em Psicologia, Universidade Federal do Rio Grande do Norte. Natal, 2011.

EVANGELISTA, D. O. Barreiras da sobrevivência: angústias e dilemas de jovens infratores pós-institucionalização. Natal, 2008. Tese (Doutorado) - Universidade Federal do Rio Grande do Norte. Natal, 2008.

FRANCISCHINI, R.; CAMPOS, H. R. Adolescente em conflito com a lei e medidas socioeducativas: limites e (im)possibilidades. PSICO, Porto Alegre, PUCRS, v.36, n.3, p.267-73, 2005.

FREUD, S. Totem e Tabu (1913). In: . Edição standard brasileira das obras psicológicas completas. v.XIII. Rio de Janeiro: Imago, 1976a. p.13-169.

Três ensaios sobre a teoria da sexualidade (1905). In: Edição standard brasileira das obras psicológicas completas. v.VII. Rio de Janeiro: Imago, 1976b. p.76152.

O estranho (1919). In: Edição standard brasileira das obras psicológicas completas. v.XVII. Rio de Janeiro: Imago, 1976c. p.273-315.

. Psicologia das massas e análise do ego (1921). In: Edição standard brasileira das obras psicológicas completas. v.XVIII. Rio de Janeiro: Imago, 1976c. p.91-183. 
FREUD, S. A negativa (1925). In: Edição standard brasileira das obras psicológicas completas. v.XIX. Rio de Janeiro: Imago, 1976d. p.293-301.

Mal-estar na civilização (1930). In: Edição standard brasileira das obras psicológicas completas. v.XXI. Rio de Janeiro: Imago, 1976e. p.81-171.

A divisão do Ego no processo de defesa (1938). In: Edição standard brasileira das obras psicológicas completas. v.XXIII. Rio de Janeiro: Imago, 1976f. p.305-13. FROTA, T. L. L. Entre o pavilhão e o inferno: trajetórias de meninos infratores no CEDUC/PITIMBU. Natal, 2006. Tese (Doutorado) - Programa de Pós-Graduação em Ciências Sociais, Universidade Federal do Rio Grande do Norte. Natal, 2006.

GUERRA, A. M. C. et al. Construindo ideias sobre a juventude envolvida com a criminalidade violenta. Estudos e Pesquisas em Psicologia, Rio de Janeiro, v.10, n.2, p.434-56, 2010 .

HEGEL, G. W. F. Fenomenologia do espirito. Petrópolis: Vozes, 2003.

HONNETH, A. Luta por reconhecimento: a gramática moral dos conflitos sociais. São Paulo. Editora 34, 2003.

JOST, M. C. Fenomenologia das motivações do adolescente em conflito com a lei. Psicologia Teoria e Pesquisa, Brasília, v.26, n.1, p.99-108, 2010.

LACAN, J. O estádio do espelho como formador da função do eu tal como nos é revelada na experiência psicanalítica. In: Escritos. Rio de Janeiro: Jorge Zahar, 1998a.

A agressividade em psicanálise. In: Escritos. Rio de Janeiro. Jorge Zahar, 1998b. 2003.

Nota sobre a criança. In: Outros escritos. Rio de Janeiro. Jorge Zahar,

LAURENT, E. O analista cidadão. Curinga, Belo Horizonte, v.1, n.13, p.7-13, EBP Seção Minas, n. 31, dezembro de 2010.

MINAHIM, M. A.; SPOSATO, K. B. A internação de adolescentes pela lente dos tribunais. Revista Direito GV, São Paulo, v.7, n.1, p.277-98, 2011.

MONTE, F. F. C. et al. Adolescentes autores de atos infracionais: psicologia moral e legislação. Psicologia Social, Florianópolis, v.23, n.1, p.125-34, 2011.

MOREIRA, J. O.; ROSÁRIO, A. B.; COSTA, D. B. Criminalidade juvenil no Brasil pós-moderno: algumas reflexões psicossociológicas sobre o fenômeno da violência. Mal-Estar e Subjetividade, Fortaleza, v.8, n.4, p.1021-46, 2008.

NOBRE, M. Luta por reconhecimento: Axel Honneth e a Teoria Crítica. In: HONNETH, A. Luta por reconhecimento: a gramática moral dos conflitos sociais. São Paulo: Ed. 34, 2003.

OLIVEIRA, M. C. R. O processo de inclusão social na vida de adolescentes em conflito com a lei. Ribeirão Preto, 2002. Dissertação (Mestrado) - Departamento de Psicologia e Educação, Universidade de São Paulo. Ribeirão Preto, 2002.

OLIVEIRA, C. S. Sobrevivendo no inferno. Porto Alegre: Sulina, 2001.

REIS, F. L. C.; MELO, D. P. S. A criança, o adolescente e a prática do ato infracional: conflitos com a lei na região sul da cidade de montes claros, $\mathrm{mg}-2012$ a 2014 . Revista Eletrônica do Curso de Direito da UFSM, Santa Maria, v.12, n.2, p.314-33, 2017. 
RIBEIRO, E. V. Reconhecimento ético e virtudes. São Paulo: Edições Loyola, 2012.

ROSA, M. D. A pesquisa psicanalítica dos fenômenos sociais e políticos: metodologia e fundamentação teórica. Mal-Estar e Subjetividade, Fortaleza, v.IV, n.2, 2004.

SAFATLE, V. Grande Hotel Abismo: por uma reconstrução da teoria do Reconhecimento. São Paulo: Martins Fontes, 2012.

SALES, M. A. (In)visibilidade perversa: adolescentes infratores como metáfora da violência. São Paulo: Cortez, 2007.

SALVADORI, M.; HONNETH, A. Luta por reconhecimento: a gramática moral dos conflitos sociais. Resenha Crítica. Conjectura, Caxias do Sul, v.16, n.1, p.189-192, jan./abr.2011.

SANTOS, T. C.; ZEITOUNE, C. M. Amor, impasses da sexuação e ato infracional na adolescência. Tempo Psicanalítico, Rio de Janeiro, v.43, n.1, p.85-108, 2011.

SEGALIN, A; TRZCINSKI, C. Ato infracional na adolescência: problematização do acesso ao sistema de justiça. Textos é Contextos, Santa Catarina, n.6, dez. 2006.

SOUZA, S. M. G. Adolescentes autores de atos infracionais: estudos psicossociais. Goiânia: Editora PUC-Goiás, 2013.

SPAGNOS, A. S. Jovens delinquentes paulistanos. Tempo Social, São Paulo, v.17, n.2, p.275-99, 2005.

TAYLOR, C. et. al. Multiculturalismo: examinando a política de reconhecimento. Lisboa: Piaget, 1998.

. Hegel e a sociedade moderna. São Paulo: Edições Loyola, 2005.

VAZ, H. C. L. Senhor e Escravo: uma parábola da filosofia ocidental. Síntese Nova Fase, Belo Horizonte, v.8, n.21, p.7-29, jan./abril 1981.

VAZ, B. G.; MOREIRA, J. S. S. Responsabilização x responsabilidades: o adolescente autor de ato infracional e a redução da maioridade penal. Psicologia Argumento, Paraná, v.33, n.82, p.346-63, jul./set. 2015.

VOLPI, M. (Org.) O Adolescente e o ato infracional. São Paulo: Cortez, 2008.

VORCARO, A.; MAZZINI, C. A.; MONTEIRO, J. P. Ato infracional e metáfora paterna. Psicologia Teoria e Prática, v.10, n.2, p.135-46, 2008.

WINNICOTT, D. W. A familia e o desenvolvimento do individuo. Belo Horizonte: Interlivros, 1980.

O ambiente e os processos de maturação: estudos sobre a teoria do desenvolvimento emocional. Porto Alegre: Artes Médicas, 1983.

. Privação e delinquência. São Paulo: Martins Fontes, 1987.

. Os bebês e suas mães. São Paulo: Martins Fontes, 1988.

. Tudo começa em casa. São Paulo: Martins Fontes, 1989.

. Natureza humana. Rio de Janeiro: Imago, 1990.

- Explorações psicanalíticas. Porto Alegre: Artes Médicas, 1994.

Pensando sobre crianças. Porto Alegre: Artes Médicas, 1997.

ZAPPE, J. G. Adolescência, ato infracional e processos de identificação: um estudo de 
caso com adolescentes privados de liberdade. Santa Maria, 2010. Dissertação (Mestrado) - Programa de Pós-Graduação em Psicologia, Universidade Federal de Santa Maria. Santa Maria, 2010.

RESUMO - O presente texto se apresenta como um trabalho teórico especulativo que pretende pensar os atos infracionais de adolescentes envolvidos com a criminalidade como forma, por vezes fracassada, de busca por reconhecimento. Acreditamos que muitas vezes o ato infracional na juventude é alimentado por um circuito de segregação e de busca por reconhecimento. Sendo assim, procuramos articular o fenômeno da violência entre os jovens com o tema da segregação social utilizando, como operador conceitual e compreensivo, a ideia de reconhecimento tal como formulada por Charles Taylor e Axel Honneth. Acreditamos, pois, que é possível escutar estes atos de uma maneira diferenciada com subsídios da clínica psicanalítica e um forte diálogo com as Ciências Sociais e a Filosofia.

PALAVRAS-CHAVE: Teoria do reconhecimento, Psicanálise, Ato infracional, Adolescência. ABSTRACT - This text is presented as a speculative theoretical work that intends to think about the infractions of adolescents involved with crime as a sometimes failed form of search for recognition. We believe that often, in youth, the offending act is fed by a circuit of segregation and search for recognition. Thus, we seek to articulate the phenomenon of violence among young people with the theme of social segregation by using, as a conceptual and comprehensive operator, the idea of recognition as formulated by Charles Taylor and Axel Honneth. We believe, therefore, that it is possible to listen to these acts in a differentiated way with inputs from psychoanalytic practice and a strong dialogue with the Social Sciences and Philosophy.

KEYWORDS: Theory of recognition, Psychoanalysis, Illegal cts, Adolescence.

Alysson Assunção Andrade é doutorando em Psicologia pela Pontifícia Universidade Católica de Minas Gerais, mestre em Filosofia pelo Programa de Mestrado em Filosofia da Faculdade Jesuíta de Filosofia e Teologia (Belo Horizonte, MG) e professor convidado dos cursos de pós-graduação da Faculdade de Pará de Minas (Pará de Minas, MG). Psicólogo, filósofo, bolsista PUC-MG. @-alyssondecampos@hotmail.com https://orcid.org/0000-0001-5605-2596

Jacqueline de Oliveira Moreira é doutora em Psicologia Clínica pela Pontifícia Universidade Católica de São Paulo, mestre em Filosofia pela Universidade Federal de Minas Gerais, professora do Programa de Pós-Graduação em Psicologia da Pontifícia Universidade Católica de Minas Gerais, psicanalista, bolsista CNPq P2, Fapemig. @ - jackdrawin@yahoo.com.br / https://orcid.org/0000-0003-0901-4217

I, II Pontifícia Universidade Católica, Belo Horizonte, Minas Gerais, Brasil.

Recebido em 27.1.2018 e aceito em 9.6.2018. 
